\title{
Molekulare Medizin
}

D er Begriff „Molekulare Medizin“ erfreut sich zunehmender Beliebtheit. Inzwischen werden Kliniken und Institute so bezeichnet, Kongresse widmen sich dem Thema und „molecular medicine“ findet sich im Titel internationaler Zeitschriften. Doch was unterscheidet eigentlich die Molekulare Medizin von der Medizin? Schließlich ist der menschliche Organismus aus Atomen und Molekülen aufgebaut. Inhaltlich betrachtet ist der Ausdruck somit beinahe allumfassend. Ein Blick in das wissenschaftliche Umfeld, aus dem er entstand, mag helfen, seine spezifischen Inhalte zu konkretisieren.

Wann der Begriff „Molekulare Medizin“ erstmals verwendet wurde und wer diesen Begriff prägte, entzieht sich der Kenntnis des Verfassers. Aber seine Verbreitung hängt eng mit der Anwendung der Nukleinsäuretechnologie - speziell der DNA-Analyse - auf menschliche Erkrankungen zusammen. Eine Krankheitsentität wird definiert durch eine oder mehrere Ursachen, einen zu den Manifestationen führenden Prozess, sowie durch die Manifestationen selbst. Bevor die DNA einer Analyse zugänglich war, erfolgte die Definition einer Krankheitsentität in der Regel „top down“. Ausgehend von den klinischen Manifestationen einer Stoffwechselerkrankung wurden zum Beispiel Aminosäuren bestimmt und Enzymdefekte nachgewiesen. In speziellen Fällen, wie beispielsweise bei Infektionskrankheiten, wurde auch der umgekehrte Weg gegangen.

Aber erst mit der Einführung der DNA-Technologie konnte der Beitrag von Mutationen und genetischen Varianten zur Ursache zum Beispiel von Erbkrankheiten und Tumoren im Sinne eines ,bottom-up“-Ansatzes analysiert werden. Es wurde möglich, den eminent wichtigen Beitrag von Genen zur Ursache von Erkrankungen zu definieren und damit ein wesentlich tieferes Verständnis genetischer Faktoren im Zusammenspiel mit Alterungsprozessen und Umweltfaktoren zu erlangen.

Hauptanwendungsgebiet der Nukleinsäuretechnologie war und ist noch immer die so genannte „molekulare Diagnostik“, also die Diagnose einer Disposition oder Manifestation einer Erbkrankheit, die Charakterisierung somatischer Mutationen in Tumoren oder auch der Nachweis von Erregern. Die Entwicklung therapeutischer Ansätze, die auf dem molekularen Verständnis von Gendefekten beruhen, braucht mehr Zeit. Mit Einführung eines Kinase-Hemmers zur Therapie der chronisch myeloischen Leukämie wurde jedoch kürzlich der „proof of principle“ für eine molekulare Therapie erbracht.

Durch die Weiterentwicklung bestehender und die Entwicklung neuer Technologien wurde die zuvor gege- bene Definition der „Molekularen Medizin“ erweitert und die Unterscheidung zwischen dem Beitrag von Genotyp und Phänotyp zur Definition einer Krankheitsentität verwischt. Eng verbunden sind diesen Entwicklungen mit dem Begriff „Komplexität“ und dem Suffix „-om“ oder „-omics“.

Nach der Aufklärung der häufigen monogenen Erkrankungen liegt der Schwerpunkt der humangenetischen Forschung nun auf polygenen Erkrankungen. Um den Beitrag genetischer Varianten zur Entwicklung dieser Erkrankungen zu erfassen, wird eine Vielzahl von Genvarianten (SNPs = ,single nucleotide polymorphisms“) parallel analysiert. Die parallele Analyse von Genen erhielt den Namen „genomics“. Das Suffix „-omics“ bezeichnet inzwischen aber ganz allgemein die parallele Analyse von Bestandteilen der Zelle wie RNA („transcriptomics“), Proteine („proteomics“), Glycane („glycomics“) oder Metabolite („metabolics“).

Während die parallele Analyse von Genen die Aufklärung von Krankheitsursachen zum Ziel hat, beziehen sich parallele Ansätze oberhalb der Ebene des Genoms auf eine verfeinerte Analyse des Phänotyps. Auf die medizinische Anwendung bezogen haben diese komplexen parallelisierten Verfahren vor allem ein Ziel: Sie sollen es möglich machen, die Disposition oder manifeste Erkrankung eines einzelnen Individuums umfassend zu verstehen - ausgehend von den möglichen Ursachen (Disposition) oder der tatsächlichen Ursache über den oder die Krankheitsprozesse bis hin zu den verschiedenen Manifestationen. Dieses „individualisierte“ Verständnis von Krankheitsentitäten soll dazu beitragen, eine einzelne Person über ihre individuellen Krankheitsrisiken aufzuklären und dem Patienten eine individuelle, auf seine Krankheit ausgerichtete Therapie zukommen zu lassen.

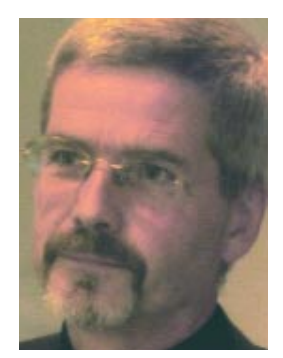

Prof. Dr. Chr. Wagener, Hamburg

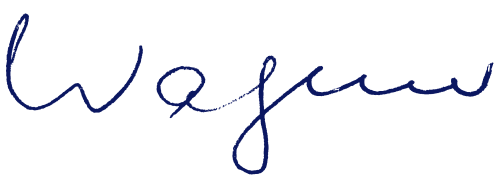

